by a student when he is there depends on the effectiveness of the tutorial guidance at the university. Mr. Ratcliffe also expressed a preference for a shorter syllabus, and a more intelligently searching kind of question. From the point of view of the university, which aims at training people to think, he felt it unfortunate that so many students go up having done physics at school; for they arrive completely misunderstanding the fundamentals, complacently superior towards the important simple things, and loving mathematical proofs for their own sake. After naming specific topics which he would like to see omitted from the Advanced Level syllabus, he said that he regards electricity as the most satisfying part of the work, since it compels a logical treatment; and he noted with interest the Science Masters' Association report on 'The Teaching of Electricity", with its logical treatment quite different from the usual historical approach.

During the discussion, Dr. H. R. Lang (secretary of the Institute of Physics) said that physics could certainly be started at the university, and the new transfer scholarship scheme of Imperial Chemical Industries, Ltd. (see Nature of March 31, p. 606) would soon be promoting this. This scheme, incident= ally, may miss some of the best boys, since those who have never done science at school might be unaware of the satisfactions it offers.

At the final session of the conference a short paper on sandwich diploma courses, by Prof. M. R. Gavin (University College of North Wales, Bangor), explained the aims and organization of the four-year courses that he had inaugurated at Birmingham, the standards expected, and the award to be given at the end. This was followed by some figures on specialization in the sixth forms of grammar schools, collected by Dr. N. Thompson (University of Bristol). He felt that the proportion of the time allotted to specialist subjects was excessive; but schoolmasters in the discussion were divided on the point, since the really relevant matter is the way the remaining time is used.

G. R. NOAKES

\section{ENRICO FERMI AND HIS CONTRIBUTIONS TO PHYSICS}

$\mathrm{H}^{\prime}$

ALF of an issue of the Reviews of Modern the memory of the late Prof. Enrico Fermi, one-time president of the American Physical Society, who died on November 29, 1954, and consists of the proceedings of the memorial symposium held at the Washington meoting of the Society on April 29, 1955, over which Prof. H. A. Bethe presided. It contains addresses by F. Seitz, E. J. Konopinski, E. Segré, W. H. Zinn and H. L. Anderson, together with photographs of sample pages from Prof. Fermi's numerous notebooks which are now being preserved in the Harper Memorial Library of the University of Chicago. The speakers were introduced individually by Prof. Bethe, who referred, in his opening remarks, to Fermi as "unique among the great physicists of the twentieth century in being one of the greatest in experimental physics and at the same time being one of the greatest theoretical physicists. He was unique also in the width of contributions. He may have been one of the last physicists who know almost all of physics and used it in his research".
Prof. Seitz spoke about Fermi statistics and its applications, and Prof. Konopinski about Fermi's theory of beta-decay, and these two lectures illustrate how two small theoretical articles originally contributed by Fermi to the Zeitschrift für Physik in 1928 and 1934, respectively, came to have such tremendous influence on the progress of physics in recent years. Profs. Segré, Zinn and Anderson deal with different aspects of Fermi's experimental work during the past twenty years. Prof. Segré gives an interesting description, including many personal reminiscences, of the work on neutrons performed by Formi and his school in Rome during 1934-35 and for which Fermi was awarded a Nobel Prize in 1938. Farly in 1939, just about the time when the nows of uranium fission reached America, Fermi arrived in the United States and became engaged on the work-atomic energy-which was to occupy his attention for the rest of his life. Prof. Zinn, in describing the part played by Fermi in the atomic energy project, considers three separate periods: the first, January 1939 to May 1942, when Fermi's work was centred on Columbia University; the second, May 1942 to the winter of 1943-44, when Fermi's work was mainly directed towards bringing about the self-sustaining chain reaction and the construction and operation of the production piles at the Hanford Engineering Works of the Manhattan Distriet ; and the third, after May 1944, when Fermi transferred to the Los Alamos Laboratory in New Mexico and finally to Chicago.

In Chicago Prof. Anderson was actively associated with Fermi and was engaged on scattering experiments using intense beams of mesons obtained from a large synchrocyclotron. Prof. Anderson describes in his talk the close personal interest, even to the actual construction with his own hands of several pieces of apparatus and the observation of various instruments, that Fermi took in the experiments. The object of the investigation was to uncover the part that $\pi$-mesons play in the nuclear interaction; and though Fermi did not live long enough to see all his predictions verified, his clear understanding of this, in addition to many other similar problems, pointed the way to the present knowledge of the pseudoscalar nature, strong coupling, short-range interaction, charge independence and causal behaviour of $\pi$-mesons.

\section{THE BOSE INSTITUTE, CALCUTTA}

7 HE thirty-eighth anniversary meeting of the foundation of the Bose Institute was celebrated on November 30, when (the late) Dr. Sunder Lal Hora delivered the seventeenth Acharya Jagadish Chandra Memorial Lecture. He chose as his subject "Conflict versus Co-operation as Factors in Evolution".

The director, Dr. D. M. Bose, in his report reviewed the activities of the Bose Institute for the past year. He said that the Institute had submitted to the Central Government plans and estimates for expansion of activities during the second five years. All the plans for expansion of the research activities of the Institute depended on the provision of additional buildings for laboratory accommodation. For this purpose additional land for building purposes is necessary, as there is very little land available in the present location of the Institute. He pointed out that to the west of the Institute the Corporation of 